\title{
Intervenciones de enfermería especializada en la prevención de endocarditis infecciosa en niños con cardiopatía congénita
}

\section{Specialized nursing interventions in the prevention of infectious endocarditis in children with congenital cardiopathies.}

\footnotetext{
Lic. Enf. Sandra Lizbeth Garcés-Guerrero• Lic. Enf. Nancy Guadalupe Rojas-Lule. EEI. Magdalena Sierra Pacheco.•
}

\section{Resumen}

En este artículo se encuentra la revisión bibliográfica respecto de medidas preventivas para coadyuvar en la disminución de riesgo de endocarditis infecciosa en niños con cardiopatía congénita. Actualmente la prevalencia de las malformaciones cardiacas reportada a nivel mundial va de 2.1 a 12.3 por 1000 recién nacidos vivos; en México con base en la tasa de natalidad, se calcula que alrededor de 10 mil a 12 mil niños nacen con algún tipo de malformación cardiaca, las cuales colocan al niño en riesgo de contraer endocarditis infecciosa. Derivado de lo anterior las intervenciones de enfermería especializada - como parte del equipo interdisciplinario - deben estar dirigidas a la prevención para evitar complicaciones que pueden llegar a tener consecuencias y secuelas graves en la salud de la persona que presenta alguna alteración en la estructura cardiaca.

Se realizó la búsqueda en diferentes fuentes de datos electrónicas como Pubmed, MEDLINE y Cochrane, así como en las distintas revistas de formato electrónico tanto nacionales como internacionales; las palabras clave introducidas fueron cardiopatías congénitas, endocarditis infecciosa, intervenciones de enfermería, prevención (infective endocarditis, children, congenital heart disease, nurse, y prophylaxis).

- Estudiante de la Especialidad en Enfermería Cardiovascular. Generación 2012.

.. Coordinadora de la Especialidad en Enfermería Cardiovascular.

FECHA DE RECIBIDO: 12 ENERO 2012

FECHA DE ENVIADO: 31 ENERO 2012

FeCHA DE ACEPTADO: 20 MARZO 2012 


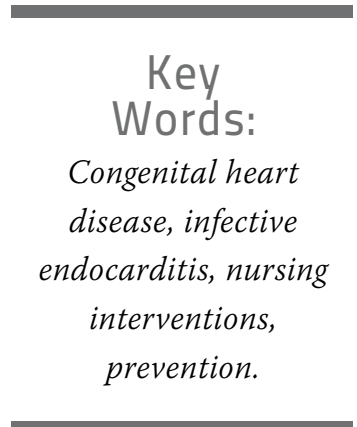

Abstract

This article is a bibliographic review on some preventive measures to assist in reducing risk of infective endocarditis in children with congenital heart disease, the prevalence of cardiac anomalies is reported worldwide from 2.1 to 12.3 per 1000 live newborns; Mexico based on the birth rate, it is estimated that around 10 to 12 thousand children with some cardiac malformation, they canpredispose the child to have infective endocarditis, it is the reason why nursing interventions, must be aimed at the prevention and avoid the expected complications that may serious consequences on the health of the person submitting any alteration in the cardiac structure. Were searched in various electronic data bases such as PubMed, Med line and Cochrane. The electronic journals both national and international; key words were introduced infective endocarditis, children, congenital heart disease, nurse, and prophylaxis.

\section{INTRODUCCIÓN}

Actualmente las malformaciones congénitas del corazón, se han convertido en un tema de relevancia, la prevalencia reportada a nivel mundial va de 2.1 a 12.3 por 1000 recién nacidos vivos. ${ }^{1}$ En nuestro país lamentablemente se desconoce la incidencia real, sin embargo el Sistema Nacional de Información en Salud (sinAis) de México reporta que en 2008 estas malformaciones son la segunda causa de mortalidad en niños menores de 1 año; la cuarta y sexta causa en edad preescolar (1 a 4 años de edad) y escolar (de 5 a 14 años) respectivamente. ${ }^{2}$

La mortalidad puede deberse a múltiples motivos todos íntimamente relacionados con la alteración en la estructura y fisiología cardiovascular, como son: insuficiencia cardiaca, choque cardiogénico, crisis hipóxicas, arritmias, endocarditis infecciosa (que puede desencadenar en sepsis y choque séptico) e hipertensión arterial pulmonar.

De los problemas antes señalados, la endocarditis infecciosa tiene una prevalencia mundial de 1.7 a 6.2 por 100000 habitantes al año, y se estima que entre un 11 al 26\% tendrán mortalidad intrahospitalaria $^{3}$ por ende las intervenciones del personal de enfermería especializado adquieren vital importancia ante la prevención de este padecimiento; de ahí el interés por realizar una búsqueda y revisión bibliográfica con la finalidad de identificar y conocer de manera más estrecha las medidas preventivas aplicables en la endocarditis infecciosa en pacientes con cardiopatías congénitas (con presencia de cortos circuitos intracardiacos) así como los cuidados específicos a los niños con alteraciones estructurales del corazón.

\section{Metodología y estrategias de búsqueda}

Se realizó una búsqueda exhaustiva en las siguientes bases de datos: Cochrane, PubMed, Biblioteca virtual de Salud México, Redalyc, Scielo, Dialnet, Medigraphic, Fisterra, Imbiomed y en Revistas Científicas como Archivos de Cardiología de México, Anales Españoles de Pediatría, Revista Española de Cardiología, Revista Argentina de Cardiología, Revista Chilena de Pediatría,
Revista de pediatría de atención primaria y Revista Española de Cirugía Oral y Maxilofacial también en los libros Manual de Urgencias Cardiovasculares y Enfermería Cardiovascular.

La búsqueda se llevó a cabo excluyendo a la endocarditis infecciosa en adultos y la no relacionada con cardiopatías congénitas. Se incluyó solamente los casos de endocarditis infecciosa en cardiopatías congénitas, utilizando las siguientes palabras clave: endocarditis infecciosa, cardiopatías congénitas, intervenciones de enfermería y prevención (infective endocarditis, children, congenital heart disease, nurse, y prophylaxis). El rango de edad seleccionado fue de 0 a 18 años. Los estudios seleccionados fueron de tipo retrospectivo, prospectivo, reporte de casos y revisiones bibliográficas.

Los artículos seleccionados fueron los considerados de mayor relevancia con relación al tema de esta revisión; posteriormente se leyó cada uno de ellos de manera crítica obteniendo datos que enriquecieron esta búsqueda, de tal 
forma que se pueda transmitir al lector información clara, oportuna y confiable. Además de aportar una fuente más de información que permita obtener un panorama más amplio de lo que hasta ahora se está haciendo por prevenir la endocarditis Infecciosa resaltando la trascendencia de las medidas médicas y de las intervenciones de enfermería para contrarrestar las complicaciones más frecuentes en niños con cardiopatías congénitas.

\section{Endocarditis infecciosa en las cardiopatías congénitas} Las Cardiopatías Congénitas (CC) son una anomalía estructural evidente del corazón o de los grandes vasos intratorácicos, con una repercusión real o potencial en la hemodinámica del niño. La prevalencia reportada a nivel mundial va de 2.1 a 2.3 por cada 1000 recién nacidos vivos (en nuestro país, se desconoce su prevalencia real). Como causa de muerte infantil, se ubica en el sexto lugar en menores de un año y como la cuarta causa en los niños entre uno y cuatro años; con base en la tasa de natalidad, se calcula que alrededor de 10 mil a 12 mil niños nacen con algún tipo de malformación cardiaca. ${ }^{1-3} \mathrm{La}$ proporción declarada de $\mathrm{CC}$ en personas con endocarditis infecciosa (EI) oscila, entre el 2 y el $18 \%$ y se clasifica en riesgo alto, moderado, bajo o nulo según la CC. ${ }^{4,5}$ (Cuadro.1)

La EI es una enfermedad inflamatoria, exudativa y proliferativa del endocardio, producida por gran variedad de microorganismos. Actualmente a nivel mundial se reporta una incidencia media de 1.7 a 6.2 por 100,000 al año, es más frecuente en hombres con una relación $2: 1$ y la mortalidad intrahospitalaria varía de $11-26 \%$ con una media de 16\%. Las lesiones más frecuentes son las verrugas o vegetaciones que se forman y crecen a través de la colonización por gérmenes en agregados de fibrina y plaquetas. Estas vegetaciones pueden localizarse en una o más válvulas cardiacas e involucrar tejidos subyacentes como cuerdas tendinosas, endocardio, miocardio y pericardio, así como en el sitio de una coartación aórtica, conducto arterioso persistente y cortos circuitos creados quirúrgicamente e incluso en una afectación vascular remota. En la gran mayoría de los casos, estos fenómenos se originan a partir de pequeñas lesiones del endotelio causadas por alteraciones hemodinámicas o presencia de material extraño intracavitario. ${ }^{6,7,8}$

Cuando el endotelio se encuentra intacto es muy difícil que se adhieran bacterias a la pared interna del vaso, pero si por alguna razón se encuentra dañado se constituye en un potente estímulo trombogénico, lo que predispone fácilmente a la formación de vegetaciones infectadas.

La lesión endotelial puede iniciarse por condiciones hemodinámicas que produzcan flujos turbulentos por estenosis o insuficiencia valvulares o vasculares o bien por comunicaciones anormales entre dos cámaras de diferente presión. El impacto de la columna sanguínea sobre válvulas deformadas las predispone a infectarse, lo que explica la preferencia de los injertos

\section{Cuadro 1. Riesgo de endocarditis infecciosa, según cardiopatía}

\section{Alto}

Válvulas protésicas

Cardiopatía cianótica

Ductus o Conducto Arterioso

Valvulopatía aórtica

Valvulopatía mitral

Comunicación interventricular

Coartación aórtica
Moderado

Bajo o nulo

Prolapso mitral con insuficiencia

Estenosis pulmonar

Valvulopatía tricuspídea

Aorta bicúspide

Miocardiopatía hipertrófica
Prolapso mitral

Insuficiencia valvular

Comunicación interauricular

Cardiopatía operada sin lesión

residual

Tomado de: Urriola V. Endocarditis y pericarditis infecciosa. Revista Chilena de Pediatría, 2000:71(2): 142-146. ${ }^{5}$ 
de endocarditis en las caras auriculares de la válvula mitral y tricúspide así como en las caras ventriculares de las válvulas sigmoideas. El choque de flujos turbulentos sobre las superficies endocárdicas favorece en esos sitios el asiento de lesiones endocárdicas. ${ }^{4,9,10}$

\section{Fisiopatología}

La EI se presenta más fácilmente cuando se conjuga un germen potencialmente infectante con la existencia de un factor predisponente; lo que producirá un implante infeccioso (por ejemplo en el borde de una válvula cardiaca, en una prótesis valvular o en un defecto septal). En la superficie de tal sitio, se origina inicialmente un proceso inflamatorio, el cual puede progresar hasta la necrosis tisular; esto a su vez, promueve un intento de reparación del organismo mediante fibrina y agregación plaquetaria lo que contribuye a una formación general de trombosis en la que también participan los factores tisulares como la tromboplastina que a su vez activa la coagulación por vía extrínseca. Entre las redes de fibrina se colonizan los gérmenes infectantes y forman vegetaciones valvulares, endocárdicas o endoteliales. A esto se continua un proceso de reparación tisular, la vegetación se convierte en un nódulo friable adherido a la superficie, cuando ésta se activa juega un papel importante en la evolución de la endocarditis.

Derivado de todo lo anterior se genera una descarga de bacterias responsables del cuadro de bacteremia y a su vez se estimula el sistema inmunológico. La vegetación (infectada) fácilmente se fragmenta y es enviada, de manera completa o en fragmentos, al torrente circu- latorio lo que condiciona eventos de embolias sépticas. Cuando estos émbolos emigran hacia la circulación sistémica, se pueden implantar en arterias de la circulación coronaria, cerebral, renal, extremidades y/o en el sistema esplácnico. Cuando ocluye un vaso de mediano o pequeño calibre, además de producirse un infarto en el territorio, puede ocasionar endarteritis séptica, formación de aneurismas y ruptura. A nivel local el proceso infeccioso puede dar lugar a ulceración, presencia de abscesos y/o destrucción del aparato valvular. ${ }^{8,11,12}$

\section{Clasificación.}

La EI se clasifica según el agente infeccioso, el tiempo de evolución, la afección valvular, y puede presentarse en personas que utilizan drogas intravenosas. ${ }^{8}$ (Cuadro 2).

\section{Valoración de Enfermería Especializada}

En la endocarditis infecciosa el primer síntoma habitualmente es la fiebre sin embargo pueden presentarse otros datos clínicos acordes a las características propias de la persona, el agente causal, el tipo de las lesiones y la localización de las mismas, por lo que la valoración y el interrogatorio por parte del profesional de enfermería a la persona portadora de una cardiopatía congénita y su cuidador primario es esencial para la detección oportuna e identificación de riesgos.

El cuidador primario (responsable directo de la atención del niño) representa una fuente de información que aporta datos valiosos que enriquecen el interrogatorio, además de ser piedra angular en la ejecución de las medidas de prevención ante complicaciones por EI en niños con cardiopatía congénita ya que por su corta edad aun son dependientes de ellos.

Durante la exploración física la presencia de enfermedades como faringitis, amigdalitis y/o caries dental (entre otras) deben ser detectadas, lo cual compromete a la enfermera especialista a realizar una valoración de manera integral y poner en práctica sus conocimientos y habilidades para orientar el cuidado que le proporcionará a la persona con problemas reales y potenciales portadora de endocarditis. ${ }^{9}$

Así la valoración exhaustiva y detallada que se realiza a la persona es de vital importancia ya que será el eje para la determinación del plan de cuidados especializados. En la inspección se deben buscar, petequias, nódulos de Osler (ganglios rojos y dolorosos en los pulpejos de los dedos de manos y pies); manchas de Roth (hemorragias retinales), pústulas, lesiones de Janeway (manchas cutáneas de color rojizo e indoloras en palmas de manos y plantas de pies), trastornos del sistema nervioso central, absceso esplénico, trastornos del sistema renal y trastornos del sistema respiratorio. En la palpación se debe valorar la presencia o ausencia de dolor abdominal, pulsos disminuidos o ausentes en extremidades, esplenomegalia o la presencia de dolor (por infarto esplénico), en ocasiones se detectan frémitos, reflujo hepatoyugular, ingurgitación yugular o edema periférico. Por lo que respecta a la auscultación según el daño producido en el endocardio, pueden aparecer soplos de insuficiencia y estenosis valvular, ocasionados por las vegetaciones localizadas en las valvas. , $^{8,10,13}$ 


\section{Cuadro 2. Clasificación de la Endocarditis Infecciosa.}

Agente causal: S. aureus, S. epidermidis, estreptococos del grupo viridans, del grupo S. pneumoniae., enterococcus sp, coxsackie B, Influenza B, Influenza A, Coxsackie A y Citomegalovirus.

A. Según el agente infeccioso

B. Según tiempo de evolución

C. Según su afección valvular

D. Endocarditis por drogas intravenosas
Endocarditis con cultivo negativo: Terapia antimicrobiana previa (causa más frecuente) descarte prematuro de cultivos (micobacterias, B. melitensis), medios de cultivo no suplementados adecuadamente (grupo HACEK, Abiotrophia sp.), bartonelosis, infecciones, infecciones por clamidias u hongos, endocarditis trombótica no infecciosa (NITE por sus siglas en idioma inglés), miocarditis viral, infección por Granulicatella elegans, endocarditis marántica, endocarditis de Libman-Sacks.

Aguda: Aquella endocarditis de curso rápido y fulminante, menor de 8 semanas. Pueden encontrarse afectadas una o múltiples válvulas, se presenta fiebre elevada, toxicidad sistémica, leucocitosis con neutrofilia. Los agentes aislados con mayor frecuencia son: $\mathrm{S}$ aureus, S. pneumoniae, S. pyogenes, N. meningitidis, H. influenzae, C.albicans.

Subaguda: Endocarditis de curso insidioso, generalmente entre 8 semanas a 1 año. Clínicamente hay hipertermia vespertina, sudoración nocturna y pérdida de peso. Los microorganismos se asientan sobre válvulas cardiacas previamente dañadas, siendo los estreptococos del grupo viridans y los enterococos, los recuperados con mayor frecuencia.

Endocarditis infecciosa en válvula nativa

Endocarditis infecciosa en pacientes con recambio valvular Endocarditis infecciosa en aquellos que utilizan drogas intravenosas. Endocarditis infecciosa nosocomial.

Los jóvenes de sexo masculino son los más afectados, y hasta $80 \%$ de ellos no se evidencian anomalías estructurales macroscópicas en las válvulas cardiacas.

Modificado de: Marcano M, Landeta J. Endocarditis Infecciosa. Vitae. Academia Biomédica Digital. 2004;19 ${ }^{8}$

Para facilitar la detección adecuada, se han estandarizado escalas basadas en una serie de criterios para lograr el diagnóstico definitivo de EI, siendo una de las más usadas y aceptadas mundialmente la sustentada en los Criterios de Duke (Cuadro 3) así como la estratificación diagnóstica de acuerdo a los hallazgos clínicos y ecocardiográficos en criterios mayores y menores que son la guía para la determinación clínica de la enfermedad.

Existen exámenes de laboratorio y gabinete que son primordiales para la detección de la EI, entre los datos que se pueden encontrar están:

- Exámenes de Laboratorio: anemia en un 70-90\% de las personas con EI. También podrían presentarse índices normocrómico, normocítico y leucocitosis y neutrofilia importante en casos agudos. La VSG (Velocidad de sedimentación globular) se incrementa hasta $55 \mathrm{~mm} / \mathrm{h}$ en casi todos los pacientes por estímulos inflamatorios de la enfermedad.

- Radiografía de tórax: puede mostrar derrame pleural e infiltrados pulmonares.

- Ecocardiograma: en el caso del ecocardiograma transtorácico es utilizado para detectar vegetaciones valvulares y el ecocardiograma transesofágico tiene mayor sensibilidad de visualizar las estructuras posteriores (como la válvula mitral).

- Electrocardiograma: puede mostrar signos de infarto agudo al miocardio ocasionados por émbolos cardiacos. ${ }^{8,9,12,14 .}$ 


\section{Cuadro 3. Criterios y estratificación de DUKE: diagnóstico clínico de endocarditis.}

\section{Criterios Mayores}

Hemocultivo positivo para Endocarditis Infecciosa:

Microorganismo típico en 2 hemocultivos separados.

Hemocultivo persistente positivo:

Hemocultivo positivo con más de 12 horas.

Tres o más con diferencia de al menos 1 hora.

Cultivo positivo para Coxiella Burnetti sólo es nece-

sario 1 hemocultivo

Datos de involucro endocárdico

Ecocardiograma demostrado masa intracardiaca oscilante o absceso, dehiscencia protésica no detectada previamente o nueva regurgitación yugular

\section{Criterios Menores}

Endocarditis previa, uso de fármacos por vía I.V, válvula protésica o lesión cardiaca responsable de flujo turbulento.

Fiebre mayor de $38^{\circ} \mathrm{C}$

Fenómeno vascular (embolismo arterial, infarto pulmonar, aneurisma micótico, hemorragia conjuntival, o lesión de Janeway).

Factores inmunológicos (glomerulonefritis, nódulos de Osler, manchas de Roth y factor reumatoide).

Hallazgos microbianos que no cumplen los criterios mayores

\section{Estratificación}

\section{Endocarditis definitiva}

Criterios patológicos: demostrar por medio de cultivos o patología, la presencia de microorganismos que confirmen endocarditis activa

Criterios clínicos: cuando el paciente:

2 criterios mayores

1 criterio mayor +3 menores

5 criterios menores

\section{Endocarditis probable}

Cumple con un criterio mayor y un criterio menor, o 3 criterios menores.

\section{Endocarditis Rechazada}

Cuando hay un diagnóstico alternativo más probable o hay resolución de los hallazgos que sugieran endocarditis, luego de 4 días de tratamiento antibiótico o cuando no hay evidencia de patología de endocarditis en la cirugía o autopsia.

Modificado de: Marcano M, Landeta J. Endocarditis Infecciosa. Vitae. Academia Biomédica Digital. 2004;19 ${ }^{8}$; Olivera C. Endocarditis infecciosa. Tratamiento y profilaxis. $2011^{10}$

El tratamiento habitual de la EI es a base de antibióticos bactericidas administrados por vía intravenosa, con lo que se busca disminuir los fracasos y las recurrencias, aplicados en un periodo de 4 a 8 semanas. Lo anterior es debido a que los gérmenes están en el interior de la matriz de plaquetas y fibrina en grandes concentraciones, con tasas de metabolismo y división celular relativamente bajos por lo que tiene una susceptibilidad disminuida a los betalactámicos y a otros antibióticos activos contra la pared celular. Se iniciará una vez conocido el ger- men responsable y según antibiograma. Si no es posible esta acción, hay que tener en cuenta que: la EI sobre válvula nativa con curso agudo, generalmente es estafilocócica y las de curso subagudo estreptocócicas. También hay que considerar que las EI precoces sobre prótesis 
valvulares (menos de 12 meses tras cirugía) son generalmente producidas por Staphylococcus. epidermidis, y las tardías (posterior a las doce semanas de cirugía) tienen un espectro similar a las EI sobre válvula nativa. Sin embargo existen reportes como el de Day, Gaureau, Shulman y Newburger que refieren que el agente de mayor incidencia ante las prótesis valvulares es el Staphylococcus Aureus. ${ }^{15}$

La endocarditis por microorganismos gramnegativos del grupo HACEK (las especies que pertenecen a este grupo incluyen varias del género Haemophilus, Actinobacillus actinomycetemcomitans, Cardiobacterium hominis, Eikenella corrodens y Kingella kingae $)^{16}$ deben tratarse con Ceftriaxona durante 4 semanas.

La EI micótica tienen mal pronóstico y la mayoría precisa tratamiento quirúrgico. El tratamiento médico de primera elección es la Anfotericina B durante 6 semanas. Dado que este antimicótico no penetra bien en las vegetaciones algunos autores recomiendan añadir 5-Fluorocitosina que actúa sinérgicamente. El Fluconazol puede ser útil en el caso de hongos susceptibles. Las endocarditis con cultivo negativo se tratan durante 4-6 semanas con Ceftriaxona y Gentamicina, añadiendo Vancomicina en caso de sospechar una estafilococia. El Linezolid se ha comenzado a utilizar con éxito en caso de gérmenes (Staphilococcus o Enterococcus) resistentes a Vancomicina. ${ }^{17}$

Recientemente se ha comenzado a utilizar el activador de plasminógeno tisular recombinante como tratamiento coadyuvante al antibiótico en el caso de EI con indicación relativa de cirugía en pacientes con alto riesgo quirúrgico.

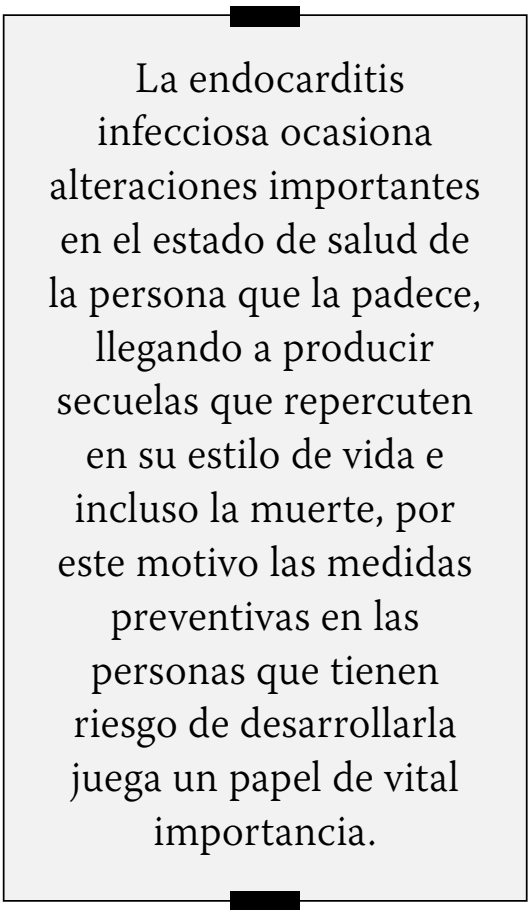

Una vez iniciado el tratamiento se debe vigilar diariamente la aparición de signos de insuficiencia cardiaca, arritmias, bloqueos o fenómenos embólicos.

Es necesario repetir los hemocultivos a los 4-6 días del inicio y a las 4 semanas del finalizado el tratamiento. Así como determinar las concentraciones séricas de los fármacos por su posible toxicidad, también es recomendable repetir la ecocardiografía a las $2^{a}, 4^{a}$ y $8^{a}$ semanas.

Se requiere tratamiento quirúrgico en algunas situaciones, siendo la indicación muy individualizadas. Algunas de las indicaciones absolutas son; insuficiencia cardiaca (sobre todo por insuficiencia valvular), obstrucción valvular; absceso perivalvular; infección micótica no candidiásica ó por pseudomona; prótesis inestable así como la ruptura del seno de Valsalva ó del tabique interventricular. Respecto de las indicaciones relativas están: bacteriemia persistente; endocarditis por Cándida; vegetaciones > de 10mm y fenómenos embólicos significativos, sobre todo si hay afectación valvular mitral y/o aórtica. ${ }^{17}$

Como se ha mostrado, la endocarditis infecciosa ocasiona alteraciones importantes en el estado de salud de la persona que la padece, llegando a producir secuelas que repercuten en su estilo de vida e incluso la muerte, por este motivo las medidas preventivas en las personas que tienen riesgo de desarrollarla juega un papel de vital importancia.

La realización de procedimientos diagnósticos ó terapéuticos que puedan inducir bacteriemias a niños con enfermedad cardiaca aumentan los riesgos de aparición de EI por lo que se deberán realizarse bajo protección antibiótica. Se recomienda administrar el fármaco una hora antes del procedimiento y no más de 6 horas después, para lograr concentraciones terapéuticas del antibiótico antes de la bacteriemia y evitar resistencias. ${ }^{18-20}$

Es un hecho en el que la mayoría de los autores coinciden que tener una malformación cardiaca es un factor de riesgo importante para el desarrollo de endocarditis. Éste riesgo puede clasificarse en: alto y moderado, dentro de las malformaciones con estos riesgos se encuentran los defectos tipo estenosis mitral pura, la valvulopatía tricúspidea, estenosis pulmonar, miocardiopatía hipertrófica, prolapso mitral con insuficiencia valvular y/o valvas redundantes, aorta bicúspide con ligeras anomalías hemodinámicas y las cardiopatías operadas sin secuelas en los primeros 6 meses tras la intervención. De manera particular algunos autores marcan a la Tetralogía de Fallot, a la comunicación interventricular 
y al conducto arterioso como las malformaciones con mayor incidencia de endocarditis. ${ }^{15,21,22}$ En las cardiopatías de riesgo bajo la profilaxis no es necesaria.

Existen además procedimientos en niños que per se tienen riesgo de bacteriemia, donde se recomienda antibioticoterapia: procedimientos dentales (extracciones dentales, procedimientos periodontales, implantes de bandas de ortodoncia, colocación de implantes o reimplantación de dientes, maniobras instrumentadas en el conducto de la raíz, limpieza profiláctica de los dientes cuando se espera hemorragia). La deficiente higiene oral en la mayoría de los niños y el consumo de alimentos ricos en sacarosa, contribuyen a aumentar el número de colonias de gérmenes en la cavidad oral, y con ello el riesgo de bacteriemia tras los tratamientos orales y las resistencias a los antibióticos en los niños presentan una extraordinaria complejidad tanto por su elevada incidencia como por sus circunstancias asociadas. Varios estudios han evaluado la prevalencia y la extensión de bacteriemias después de diferentes procedimientos dentales en niños; los tratamientos conservadores odontológicos, en los que se colocan o retiran bandas, pueden originar bacteriemia en un número significativo de niños. En una extracción sencilla de un diente, aparece bacteriemia en un 40-50\% de los niños examinados. Los niveles más altos de bacteriemia se encuentran tras las inyecciones intraligamentarias en procedimientos de anestesia local (96,6\% de los niños). En más del 50\% de los casos se aislaron estreptococos del grupo viridans. El nivel de higiene oral influye en los niveles de bacteriemia considerablemente. ${ }^{23,24,25,26}$ Así mismo en procedimientos quirúrgicos que afecten a la mucosa respiratoria (amigdalectomía, adenoidectomía, broncoscopia rígida, broncoscopia flexible con biopsia), procedimientos digestivos y genitourinarios (esclerosis de varices esofágicas, dilatación esofágica, cirugía de las vías biliares, cirugía en mucosa intestinal, cistoscopia, dilatación uretral) requieren de profilaxis antimicrobiana.

Es importante mencionar aquellos procedimientos que a pesar de ser invasivos no es necesario aplicar ningún tipo de profilaxis como es el caso de retiro de puntos de sutura, extracción de primera dentición y ecocardiograma transesofágico. ${ }^{17,20}$

Cabe mencionar, que hay recomendaciones adicionales ${ }^{5,23,24}$ que la enfermera especialista debe de proporcionar al cuidador primario, con la finalidad de fomentar el bienestar y evitar complicaciones en el niño, están dirigidas al manejo odontológico en portadores de cardiopatía congénita:

1. Los niños mayores que van a operarse pueden ser revisados uno o dos meses antes por el odontólogo a fin de tratar sus posibles caries antes del período de máximo riesgo de endocarditis, que ocurre tras la cirugía.

2. Establecer y mantener la mejor salud buco-dental posible.

3. Realizar cepillado dentario 2 veces por día utilizando adecuadamente: cepillos (blandos, cortos con cerdas parejas), hilos y dispositivos para la remoción de placas

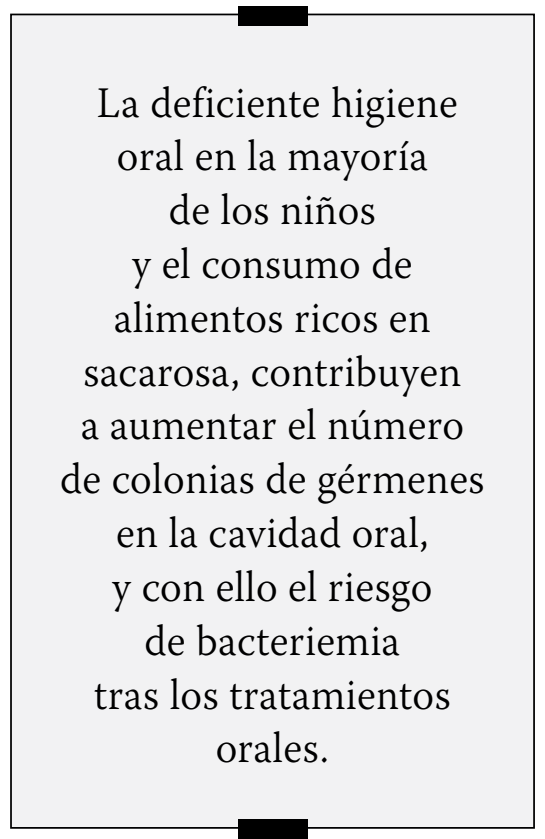

bacterianas dentales, palillos interdentarios así como pastas dentales según indicaciones del odontólogo. Esto es de suma importancia pues una inadecuada higiene dental puede resultar en enfermedad periodontal y periapical.

4. Se recomienda utilizar pastas dentales que incluyan en su composición: fluor, dado que evita la adhesión al esmalte de la placa bacteriana que se forma cada 8 horas (independientemente de las comidas). En caso de presentar enfermedad gingival $y / o$ periodontal utilizar pastas dentales y/o geles conteniendo clorhexidina o tricloxan durante el cuadro por periodos no superiores a 40 días.

5. Efectuar consulta odontológica cada 3 meses. La incidencia y magnitud de las bacteriemias de este origen son directamente proporcionales al grado de enfermedad buco-dental (periodontal y periapical). Tratar por ello de 
remover todo foco infeccioso que asiente en tejidos duros y blandos: encía, periodonto, carrillo, piso de boca, lengua y paladar.

6. En la medida de lo posible minimizar el grado de trauma infringido en este grupo de pacientes durante procedimientos odontológicos, dada su directa relación con la ocurrencia de bacteriemia.

7. Se recomienda el enjuague bucal con solución de clorhexidina al $0.12 \%$ en las 48 horas previas a procedimientos odontológicos: colutorios con $15 \mathrm{ml}$ de dicha solución pura durante 30 segundos dos veces por día y uno 30 segundos antes del mismo, ya que ello puede reducir la incidencia y magnitud de bacteriemias ocasionadas por los mismos.

8. Si son necesarios varios procedimientos odontológicos es recomendable, siempre que sea factible, mantener un intervalo de entre 9 y 14 días entre sesión y sesión para evitar la potencial emergencia de gérmenes resistentes a la profilaxis con antibióticos utilizada, realizando en cada sesión el mayor número de procedimientos posibles.

9. En caso de requerir más procedimientos en un lapso mayor a 14 días indicar antibióticos diferentes previos a cada una de las sesiones odontológicas.

10. Ocasionalmente un paciente puede estar recibiendo antibiótico en el momento de realizarse los procedimientos odontológicos. Si el mismo es un antibiótico habitualmente utilizado para la profilaxis de endocarditis infecciosa es preferible seleccionar una droga de otro grupo por la posibilidad que su cavidad oral se encuentre colonizada por microorganismos resistentes.

11. Otra opción es posponer el procedimiento odontológico, realizándolo 9 a 14 días después de completado el tratamiento con antibióticos.

12. Los pacientes desdentados así como los portadores de aparatos de ortodoncia fijos o removibles pueden desarrollar bacteriemias a partir de úlceras originadas por prótesis inadecuadas. Dichos pacientes deben ser examinados periódicamente por el odontólogo para corregir cualquier problema que pueda causar ulceración de la mucosa.

Por todo lo antes mencionado, resulta fundamental educar a este grupo de personas y al cuidador primario; para que puedan identificar y comprender las situaciones de riesgo enumeradas y las conductas frente a las mismas.

Si bien, esta revisión bibliográfica está enfocada a la prevención de la EI, no podemos dejar pasar desapercibido el mencionar y hacer énfasis en las complicaciones con las que frecuentemente nos encontramos en la práctica clínica, ya que la mortalidad registrada oscila entre el 20 y $30 \%$ al año ${ }^{16}$ es por eso que a continuación compartimos las complicaciones más comunes:

Insuficiencia Cardiaca: exacerbación en el caso de los niños con lesiones congénitas que ya la presentaban y se encontraban estabilizados con tratamiento.
Absceso Perivalvular: la válvula aórtica y su anillo son las estructuras más susceptibles para la formación de un absceso, ya que puede extenderse al tejido adyacente, es posible encontrar grados variables de bloqueo aurículoventricular, es especial cuando se afecta la valva derecha y la no coronariana de la válvula aórtica.

Otras complicaciones extravalvulares: entre éstas raramente reportadas se encuentran la disección de la válvula aórtica, abscesos intraluminales de la aorta torácica descendente, la pericarditis supurativa o no supurativa, que produce dolor o tamponade cardiaco, además de formar conexiones fistulosas intracardiacas debido a la extensión de la infección de la válvula hacia el miocárdico adyacente que puede producir aneurismas, seudoaneurisma o incluso perforación miocárdica.

Embolización: el embolo consistente en fragmentos de la vegetación puede ocluir cualquier vaso sanguíneo en circulación sistémica o pulmonar y como consecuencia puede producir accidente cerebrovascular, ceguera, isquemia arterial aguda de cualquier extremidad, síndromes dolorosos inusuales por infarto esplénico o renal, hipoxemia por embolia pulmonar o parálisis por afección de la médula espinal.

Complicaciones Neurológicas: estas incluyen evento embolico isquémico comúnmente de la arteria cerebral media, encefalopatía aguda, meningoencefalitis, meningitis aséptica o purulenta, hemorragia cerebral, absceso cerebral y convulsiones. La mortalidad al año de las personas con complicaciones neurológicas a causa de EI es del 20 
al 50\%. La mortalidad de las personas con complicaciones neurológicas durante Aneurismas Micóticos se presenta de un 3 a 15\% con la extensión y ruptura del aneurisma que puede ser una complicación a nivel cerebral.

Complicaciones Renales: puede ocurrir infarto renal por embolia, nefritis aguda inducida por medicamentos, glomerulonefritis por complejos inmunes y absceso renal, reportándose insuficiencia renal en un tercio de las personas con EI. ${ }^{8,9,17}$.

Respecto a las intervenciones de enfermería en pacientes con EI, en el año 2005 se documentó por la Dirección de Enfermería del Hospital Universitario "Ramón y Cajal" en Madrid, los siguientes diagnósticos de enfermería como parte de un Plan de Cuidados a una persona con EI:

Alto riesgo de disminución del gasto cardiaco relacionado con la inflamación del endocardio y cambios en la estructura de las válvulas cardiacas y aumento del trabajo miocárdico.

Riesgo de ingesta nutricional inadecuada relacionado con anorexia.

Ansiedad relacionada con enfermedad aguda y hospitalización.

Infección relacionada con shunt bidireccional manifestado por presencia evidente o sugestiva de vegetaciones en válvulas o tejidos adyacentes, fiebre, leucocitosis y hemocultivos positivos.

Hipertermia relacionada con proceso infeccioso manifestado por taquicardia, aumento de la temperatura corporal y estado hiperdinámico. ${ }^{27}$

Estas respuestas humanas coinciden con lo reportado por autores japoneses en un estudio de cohorte que tuvo por objetivo identificar la presentación clínica de la EI para realizar futuras guías de prácticas clínicas. $^{28}$

\section{Intervenciones de Enfermería Especializada}

Éstas forman parte del proceso de atención de Enfermería el cual constituye la herramienta de trabajo base para el ejercicio profesional, permitiendo a la enfermera no sólo identificar los problemas derivados del efecto del proceso salud-enfermedad sino también planear, ejecutar, evaluar y prevenir complicaciones proporcionado cuidados de enfermería oportunos. Sin embargo posterior a la búsqueda realizada no se identificaron publicaciones que señalen la participación del profesional de enfermería para evitar el daño cardiovascular; por tal motivo proponemos algunos diagnósticos enfermeros e intervenciones en la etapa de prevención de la endocarditis infecciosa.

\section{Diagnóstico 1.}

Conocimientos deficientes acerca de la enfermedad congénita y riesgos a la salud relacionados con poca familiaridad con los recursos para obtener la información.

Objetivo: La persona y/o el cuidador primario verbalizará los conocimientos acerca de su enfermedad congénita y medidas de prevención de complicaciones durante sus valoraciones médicas periódicas.

\section{Intervenciones de enfermería:}

- Evaluar el nivel de conocimiento en relación a su enfermedad.
- Pedir a la persona describa con sus palabras su enfermedad, así como signos y síntomas de alarma.

- Instruir sobre enfermedad, signos y síntomas que se pueden presentar

- Informar a la persona y su familia acerca de la presencia de enfermedad cardiaca subyacente, la cual sumada a ciertos procedimientos (odontológicos, medios diagnósticos, etc), constituye un riesgo de contraer EI.

- Pedir a la persona siempre informe oportunamente al personal de salud que es portador de EI en caso de cualquier procedimiento médico al que se someta por más simple que éste parezca.

- Informarle acerca de los cambios que se pueden generar después de resuelto el problema quirúrgico.

- Reevaluar el nivel de conocimiento en relación a su enfermedad, después de realizar las anteriores intervenciones.

- Pedir a la persona enlistar medidas de prevención de su enfermedad. ${ }^{13}$

\section{Diagnóstico 2.}

\section{Riesgo de colonización} bacteriana de tejido cardiaco relacionado con exposición a procedimientos dentales Objetivo: Prevenir la aparición de vegetaciones bacterianas en la persona con factores para desarrollar endocarditis infecciosa.

\section{Intervenciones de enfermería:}

- Identificar los factores de riesgo que presenta la persona 
para desarrollar endocarditis.

- Interrogar a la persona y/o cuidador primario si se sabe con alguna afección cardiaca congénita.

- Determinar el grado de riesgo según escala de clasificación.

- Verificar la prescripción con antibioticoterapia.

- Fomentar en la persona y cuidador primario el apego al tratamiento.

- Higiene bucal adecuada y visita periódica al dentista.

- Enfatizar la importancia de las revisiones médicas periódicas con el cardiólogo pediatra.

\section{Diagnóstico 3.}

Riesgo de deterioro de la perfusión tisular (cerebral, renal, etc.) relacionado con émbolos sépticos.

Objetivo: Disminuir el riesgo de complicaciones en la persona con cardiopatía congénita mediante el diagnostico, vigilancia y tratamiento oportuno.

\section{Intervenciones de enfermería:}

- Valoración neurológica periódica.

- Valorar aspecto de la orina, pruebas de función renal y pruebas de coagulación.

- Informar los cambios de comportamiento, dificultad respiratoria o presencia de hematuria.

\section{Discusıón}

Dentro de la revisión bibliográfica consultada, documentos de consenso, y estudios realizados se encontró que los autores coinciden en que los niños con una cardiopatía congénita, principalmente: comu- nicación interventricular, portadores de prótesis valvulares, tetralogía de Fallot y afecciones aorticas, tienen mayor riesgo de presentar EI.

Además concuerdan que la profilaxis con antibióticos es esencial para disminuir el riesgo en este grupo de personas, principalmente en los procedimientos odontológicos que llegan a presentar hemorragia, o aquello en los que se usó anestésicos locales así como también en la colocación de dispositivos de ortodoncia. Se recomienda el uso de penicilina previo al procedimiento con una dosis inicial de carga que es variable dependiendo del tipo y duración del procedimiento así como del tipo de cardiopatía congénita.

Se hace especial énfasis en la higiene bucal, para evitar que las bacterias que se encuentran en la cavidad oral pasen al torrente sanguíneo, en niños pequeños, se recomienda hacer limpieza con un paño para mantener la boca limpia; el cepillado dental en niños mayores de 1 año se deberá realizar cuatro veces al día con un cepillo de cerdas suaves; evitar en la medida de lo posible la ingesta de azucares, el uso de chupón y biberón para prevenir la formación de caries dental.

Uno de los estudios ${ }^{26}$ concluye que a pesar de que las guías de proxilaxis antimicrobiana recomiendan dicha práctica, no se encontró suficiente evidencia que respalde su indicación cuestionando así el riesgo-beneficio que ésta representa. Por lo que nos da un eje de partida para sustentar y unificar las medidas de prevención para EI en pacientes con alteraciones cardiacas congénitas y reafirmar las actuales medidas de prevención.

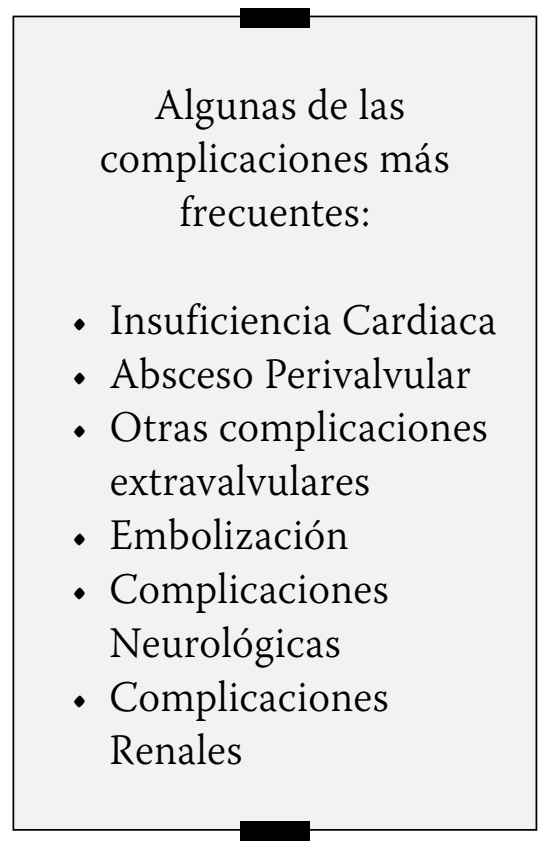

\section{ConCLusión}

Durante esta revisión se logró crear un panorama más amplio de la bibliografía, estudios y acciones que actualmente se llevan a cabo en distintas partes del mundo en pacientes que desarrollan endocarditis infecciosa relacionada a una cardiopatía congénita, además de conocer las medidas preventivas y los cuidados de enfermería en este tipo de afecciones cardíacas.

Es evidente que la endocarditis infecciosa continúa siendo un desafío para los profesionales de la salud involucrados en la atención de las personas con esta afección. Sus características clínicas inespecíficas, los cambios casi constantes en aspectos epidemiológicos y su causa infecciosa hacen compleja la atención de este padecimiento; por ende exigen mayor esfuerzo del equipo multidisciplinario responsable.

Por otro lado los avances en el diagnóstico clínico, microbiológico e imagenológico y en el campo de la administración de la profilaxis y el tratamiento, tanto médico como 
quirúrgico, obligan a estar en permanente disposición para estudiar e investigar en este campo, que cada vez más es explorado por las complicaciones más frecuentes que se presentan con relación a las cardiopatías congénitas como insuficiencia cardiaca, abscesos perivalvulares, embolizaciones sépticas, complicaciones neurológicas, renales y extravalvulares las que se pueden contrarrestar con la implementación de las medidas adecuadas de prevención como la profilaxis antibiótica, las valoraciones médicas frecuentes y el fomento a la higiene oral óptima, ya que este último es el factor más importante en la prevención de complicaciones como consecuencia de una bacteriemia; en opinión de algunos autores esta medida resulta ser más importante cuando se trata de prevenir endocarditis infecciosa que la administración antibióticos preintervención dental.

Es preciso hacer énfasis en la importancia de identificar y trabajar con los niños portadores de cardiopatías congénitas y su cuidador primario, brindando educación y orientación acerca del tipo de malformación presente, de tal manera que logren identificar los riesgos que conlleva el someterse a diversos procedimientos, por inofensivos que parezcan.

Finalmente como autoras de este trabajo queremos enfatizar el papel de la enfermera especializada como educadora, y el valor de prevenir nuevos eventos infecciosos mediante estrategias educativas personalizadas que permitan a la persona reflexionar acerca de su autocuidado y calidad de vida dando mayor importancia a las intervenciones de enfermería como pauta del cuidado especializado, y así poder impactar en la disminución de la incidencia de este padecimiento.

Los niños portadores de cardiopatías congénitas y su cuidador primario, requieren educación y orientación acerca del tipo de malformación presente, de tal manera que logren identificar los riesgos que conlleva el someterse a diversos procedimientos, por inofensivos que parezcan

\section{Referencias Bibliográficas}

1 Calderón J, Cervantes-Salazar J, CuriCuri P, Ramírez-Marroquín S. Problemática de las cardiopatias congenitas en México. Propuesta de regionalización. Arch Cardiol Mex [revista en Internet]. 2010 [consultado 2012 Feb 12]; 80(2):133-140. Disponible en: http://bit.ly/Syxi1G

2 Sistema Nacional de Información en Salud. Principales causas de mortalidad en menores de un año, en niños de 1 a 4 años y en escolares. México: Secretaría de Salud, 2008. Disponible en: http://bit.ly/pN6DI1

3 Perich R. Cardiopatías congénitas más frecuentes. Pediatr Integral [revista en internet]. 2008 [consultado 2012 ene 21];12(8):807-18. Disponible en: http://bit.ly/ShRSJV

4. Herranz Jordán B. Control de los niños con cardiopatía congénita en Atención Primaria. Rev Pediatr
Aten Primaria [revista en Internet]. 2009 Dic [consultado 2012 enero 21]; 11(44): 639-655. Disponible en: http://bit.ly/RvAUoR

5 Urriola P. Pericarditis y endocarditis infecciosa. Rev. chil. pediatr. [revista en Internet]. $2000 \mathrm{Mar}$ [consultado 2012 febrero 1]; 71(2): 142-146. Disponible en: http://bit. ly/SYEyEv

6 Habib G, Hoen B, Tornos P, Thuny F, Prendergast B, Vilacosta I et al. Guía de práctica clínica para prevención, diagnóstico y tratamiento de la endocarditis infecciosa. Rev Esp Cardio, [revista en Internet] 2009 [consultado 2012 febrero 5]; 62(12):1465.e1-.e54. Disponible en: http://bit.ly/LP2Spy

7 González-Aguilar A, Aguilar C, Lizardi J. Endocarditis bacteriana. Reporte de un caso y revisión en la literatura. Médica Sur, [Internet] 2005 [consultado 2012 enero 30]; 12 (3) 172-6 disponible en: http:// bit.ly/KRupbE

8 Marcano M, Landeta JM. Endocarditis Infecciosa. Vitae. Academia Biomédica Digital. 2004;19[Internet]. [consultado 2012 febrero 1]; 1-26. Disponible en: http://bit.ly/ L8Y5Uf

9 Ruiz M. Complicaciones agudas de la endocarditis infecciosa. 4a. Ed. Guadalajara Boo JF. Manual de Urgencias Cardiovasculares. México: McGraw-Hill Interamericana, 2008. pp. 201-9

10 Olivera C. Endocarditis infecciosa. Tratamiento y profilaxis. Capitulo 41 [Internet]. 2011[consultado 2012 febrero 21]; 581:603. Disponible en: http://bit.ly/JYwH7E

11 Castaño, R. Guía de práctica clínica Diagnóstico y tratamiento de la endocarditis infecciosa. México Secretaria de Salud, [Internet]. 2010. [consultado 2012 febrero 5] 
; 1:52 Disponible en: http://bit.ly/ SwsTNl

12 Carbajal-Pruneda P, Chávez-Tapia N, Lizardi-Cervera J. Endocarditis Infecciosa. Medica Sur[revista en Internet]. 2004 Oct-Dic[consultado 2012 febrero 21] ; 11(4):249:251. Disponible en: http://bit.ly/KRvFLS

13 Rincón F. Enfermería Cardiovascular. Atención de enfermería en el postoperatorio de cirugía cardiovascular. 21 a. Ed. Carmargo F. Montañez Z. Colombia: Editorial Distribuna, pp. 405:415.

14 Perdomo-García F, Martínez-Muñiz J, Machín-Rodríguez J, TorralbasReverón F, Díaz-Ramírez S. Endocarditis Infecciosa. Una revisión bibliográfica necesaria. Medisan, Cuba[Internet]. 2010[consultado 2012 febrero 21];14(1):90:9. Disponible en: http://bit.ly/N8fsQq

15 Day M, Gauvreau K, Shulman S, Newburger J. Characteristics of Children Hospitalized with Infective Endocarditis. Circulation [revista en Internet]. 2009 Feb [consultado 2012 febrero 27]; 119:865-870. Disponible en: http:// bit.ly/QTiwnj

16 Tamar F. Barlam, Dennis L. Kasper. Infecciones debidas a microorganismos del grupo HACEK y diversas bacterias gramnegativas. Capítulo 140. Fauci, Braunwald, Kasper, Hauser, Longo, Jameson, y Loscalzo, (Eds). Harrison Principios de Medicina Interna.17a edición. McGraw-Hill Interamericana. Disponible en: http://bit.ly/ SMzrNx

17 Olivera-Avezuela C, Lubian-López S. Endocarditis Infecciosa tratamiento y profilaxis. En: Zabala Arguelles JI. (Coord) Protocolos diagnósticos y terapéuticos en cardiología pediátrica. [Internet] s/a [consultado 2012 Febrero 19] ; 24:1-14. Disponible en: http://bit. ly/LTfOhw

18 Citak M, Rees A, Mavroudis C. Surgical management of infective endocarditis in children. Ann Thorac Surg [revista en Internet]. 1992 [consultado 2012 Febrero 27] ; 54:755-760. Disponible en: http:// bit.ly/PSQp8F

19 Valente AM, Jain R, Scheurer M, Fowler VG, Corey R, Bengur R et al. Frequency of Infective Endocarditis Among Infants and Children with Staphylococcus aureus Bacteremia. Pediatrics [revista en Internet]. 2005 January [consultado 2012 Febrero 27] ; 115(1): e15-e20. Disponible en: http://bit.ly/QFlTkk

20 Clara L. et al. Consenso de Endocarditis Infecciosa. Comisión de profilaxis. Rev Argen Cardiol [revista en Internet] 2002 [consultado 2012 Mayo 11] ; 70(5):53-60. Disponible en: http://bit.ly/MYy1Xp

21 Aguilar J, Summerson C. Comunicación interventricular y endoarteritis valvular aórtica, como causa de embolia sistémica y pulmonar. Arch Cardiol Mex[Internet]. 2005 Jul - Sep [consultado 2012 Febrero 21]; 75(3):371-2. Disponible en: http://bit.ly/MfOaxF

22 Cabrera A, Aramburu-Arriaga, N, Martinez P, Alcíbar J, Angulo P. Endocarditis infecciosa en un paciente pediátrico con atresia pulmonar y comunicación interventricular corregidas con un conducto valvulado. An Esp Pediatr [internet]. 1998 Abr [consultado 2012 febrero 21];(49):182:4. Disponible en: http://bit.ly/L4fqfq

23 Gutiérrez JL, Bagán JV, Bascones A, Llamas R, Morales A, Noguerol $\mathrm{P}$, et al. Documento de consenso sobre la utilización de profilaxis antibiótica en cirugía y proce- dimientos dentales. Rev Esp Cir Oral y Maxilof [revista en Internet] 2006 [consultado el 2012 enero 12] ; 28(3):151-181. Disponible en: http://bit.ly/K2WEBh

24 Al-Karaawi ZM, Lucas VS, Gelbier M, Roberts GJ. Dental procedures in children with severe congenital heart desease: a theoretical analysis of prophylaxis and non-prophylaxis procedures. Heart 2001; 85(1):66-8 Disponible en: http://1. usa.gov/SwJhgW

25 Van der Meer JTM. Prophylaxis of endocarditis. The Netherlands Journal of Medicine 2003; 60(11): 423-7. Disponible en: http://bit.ly/ QTpBEp

26 Oliver R, Roberts GJ, Hooper L, Worthington HV, Antibiotics for the prophylaxis of bacterial endocarditis in dentistry. Base de datos de revisiones sistemáticas Cochrane. [Internet] 2008 [consultado 2012 enero 12]: 4 Arte. No: CD003813. DOI:10.1002/14651858CD003813. pub3. Disponible en: http://bit.ly/ LRL3Wg

27 Hospital Universitario "Ramón y Cajal”. Dirección de Enfermería. Plan de cuidados estandarizado en paciente con endocarditis. Madrid [Internet]. 2005 Dic 12 [consultado 2012 Febrero 1];1:9. Disponible en: http://bit.ly/LlOLsz

28 Niwa K, Nakazawa M, Tateno S, Yoshinaga M, Terai M. Infective endocarditis in congenital heart disease: Japanese national collaboration study. Heart 2005; 91:795800. Disponible en: http://1.usa. gov/SV2y0A 